\title{
Alfabetização matemática e literatura infantil: possibilidades para uma prática pedagógica integrada
}

Literacy mathematics and literature child: possibilities for a teaching integrated

\author{
Fabio Colins ${ }^{1}$ \\ Arthur Gonçalves Machado Jr. ${ }^{2}$ \\ Tadeu Oliver Gonçalves ${ }^{3}$
}

\section{Resumo}

Este artigo tem como objetivo apresentar, descrever e discutir sobre o ensino integrado de alfabetização matemática e alfabetização linguística por meio da literatura infantil no que concerne, especificamente, o ensino de geometria. As propostas didáticas apresentadas nesta pesquisa abordam o ensino de geometria (Espaço e Forma), especificamente as habilidades relacionadas à localização e movimentação no espaço, reconhecimento, composição e decomposição de figuras planas e seus elementos (aresta, vértice, lado etc.) a partir da leitura de dois textos de literatura Infantil. A experiência docente deu-se por meio de duas sequências de atividades construídas com o propósito de desenvolver um ensino integrado de alfabetização matemática e alfabetização linguística em uma turma multisseriada composta por alunos do $1^{\circ}, 2^{\circ}$ e $3^{\circ}$ anos do Ensino Fundamental. Nesta pesquisa percebemos que é possível trabalhar a disciplina matemática de maneira contextualizada e integrada com a língua portuguesa por meio da literatura infantil.

Palavras chave: Alfabetização matemática; literatura infantil; prática pedagógica integrada.

\section{Abstract}

This paper aims to present, describe and discuss the integrated teaching math literacy and linguistic literacy through children's literature regarding specifically the teaching of geometry. Didactic proposals in this research approach the teaching of geometry (Space and Shape), specifically the skills related to the location and movement in space, recognition, composition and decomposition of plane figures and their elements (edge, vertex, side, etc.) from reading two Children's literature texts. The teaching experience was given by two sequences of activities built with the purpose of developing an integrated teaching math literacy and linguistic literacy in a multisseriate class composed of students of the $1^{\text {st }}, 2^{\text {nd }}$ and $3^{\text {rd }}$ year of elementary school. In this research we realized that you can work the mathematical discipline of contextualized and integrated way with the English language through children's literature.

Keywords: numeracy; children's literature; integrated pedagogical practice.

\footnotetext{
1 formador.ufpa@gmail.com

2 agmj@ufpa.br

3 tadeuoliver@yahoo.com.br
} 


\section{Introdução}

Por muito tempo se falou em alfabetização apenas como aprender a ler ou a escrever em língua materna, e pouco se dava importância à alfabetização matemática, mas essa área do conhecimento tem sua linguagem específica. Portanto, o processo de alfabetização das crianças do primeiro ciclo do ensino fundamental ( $1^{\circ}$ ao $3^{\circ}$ anos) precisa perpassar por um processo interdisciplinar. Nesse sentido, partimos do pressuposto de que o trabalho integrando a matemática e a literatura infantil já seria um bom começo. Nesse sentido, as crianças quando inseridas no processo de alfabetização matemática precisam ser levadas a mobilizar saberes matemáticos relacionados à construção da noção de número e suas funções nas práticas sociais, às operações com esses números, à leitura de mapas, gráficos, tabelas e à movimentação e localização no espaço.

Nesse sentido, o professor alfabetizador precisa propor uma alfabetização matemática integrada à alfabetização em língua materna por meio de práticas de leitura. Mas como é possível desenvolver um trabalho de alfabetização matemática e linguística de forma integrada? Partindo desse questionamento, o presente artigo tem como objetivo apresentar, descrever e discutir sobre as práticas de alfabetização matemática e alfabetização linguística por meio do letramento literário no que concerne, especificamente, o eixo espaço e forma: a localização e a movimentação do espaço (considerando mais de um ponto de referência), reconhecimento de figuras planas e seus elementos geométricos etc. Todas essas habilidades do campo geométrico precisam estar conectadas ao processo de leitura de textos de diversos gêneros textuais. Para isso, saber ler e escrever não basta, as crianças precisam saber fazer uso dessas habilidades para responder às exigências de leitura e de escrita que são feitas pela sociedade diariamente. Mas o que consideramos como alfabetização matemática na perspectiva do letramento literário?

\section{Alfabetização Matemática na perspectiva do Letramento Literário}

O que consideramos como alfabetização matemática na perspectiva do letramento literário não é somente utilizar nas aulas de matemática textos para ensinar, mas aprender matemática para ler os textos de literatura. Para isso faz-se necessário que o professor alfabetizador, durante todo o processo de alfabetização matemática, possibilite aos seus alunos um trabalho integrando práticas de leitura e os conteúdos matemáticos: números e operações, grandezas e medidas, geometria e o tratamento da informação. Esses são, segundo os Parâmetros Curriculares Nacionais ( $\mathrm{PCN}$ ), os quatro grandes blocos de conteúdos que constituem as habilidades necessárias no processo de alfabetização matemática. No que concerne, especificamente ao bloco de conteúdos sobre geometria, a criança em processo de alfabetização matemática precisa, por meio de atividades integradas de matemática e literatura infantil, mobilizar saberes matemáticos relacionados à composição e decomposição de figuras geométricas planas; à leitura de informações em mapas; à construção e representação de figuras geométricas não planas; à movimentação e localização no espaço utilizando um ou mais pontos de referência e à criação de itinerários etc. (BRASIL, 1997).

Esses saberes matemáticos relacionados à alfabetização matemática precisam ser trabalhados de tal forma que os professores alfabetizadores criem rotinas de leitura nas aulas leitura individual, compartilhada, silenciosa, desafiadora etc. Além disso, explorar nos 
textos, além das ideias sobre o conteúdo matemático, novas informações, aprendizagens e conhecimentos de como organizar o saber matemático.

Para Fonseca (2014), a relação entre a leitura e escrita em matemática apresenta relevância por sua inferência nas práticas de leituras escolares. De fato, há textos que circulam pela sociedade e apresentam uma linguagem matemática, mas essa linguagem só ajuda a constituir sentido para aqueles que conseguirem mobilizar os conhecimentos matemáticos durante a leitura, e são estes mesmos conhecimentos que podem auxiliar na resolução de problemas da área da matemática. No entanto, o trabalho integrando alfabetização linguística e matemática pode ser realizado por meio da literatura infantil.

A alfabetização matemática por meio da literatura infantil pode ser integrada à alfabetização em língua materna, mas requer do professor alfabetizador um planejamento bem elaborado. Além disso, é necessário que o educador também aprecie poemas, selecione textos de qualidade (textos adequados à idade das crianças), planeje e organize espaços e situações que favoreçam uma alfabetização na perspectiva do letramento literário. Para Faria (2012), é de grande importância o professor ter uma formação literária básica para saber analisar os livros infantis, selecionar o que pode interessar às crianças num momento dado e decidir sobre os elementos literários que sejam úteis para ampliar o conhecimento do leitor e mobilizar saberes de outras áreas, por exemplo, da matemática. Neste sentido, a literatura infantil pode ser uma estratégia de garantir um ensino de matemática que faça sentido para quem está aprendendo e que dê significado aos conteúdos matemáticos ensinados. Para Lopes (2009):

\begin{abstract}
A leitura de textos que tenham como objeto conceitos e procedimentos matemáticos, história da matemática ou reflexões sobre a matemática, seus problemas, seus métodos, seus desafios pode, porém, muito mais do que orientar a execução de determinada técnica, agregar elementos que não só favoreçam a constituição de significados dos conteúdos matemáticos mas também colaborem para a produção de sentidos da própria matemática e de sua aprendizagem pelo aluno (LOPES, 2009, p. 66).
\end{abstract}

Além de dar sentido e significado ao que se aprende e ao que se ensina, a literatura infantil possibilita um contexto em que o aluno se expressa de maneira natural e informal por meio de uma leitura lúdica e dinâmica. Porém, proporcionar aos alunos a alfabetização matemática e linguística de maneira integrada é um dos grandes desafios enfrentados pelos professores que ensinam matemática nos anos iniciais do ensino fundamental.

\title{
Encaminhamentos Metodológicos
}

A investigação é resultante de uma prática de sala de aula de um professor alfabetizador que leciona numa turma multisseriada de uma escola da rede municipal de ensino situada no município de Muaná-Marajó-Pará-Brasil composta por alunos do $1^{\circ}, 2^{\circ} \mathrm{e}$ $3^{\circ}$ anos do ensino fundamental. A instituição escolar onde ocorreu a prática aqui apresentada fica situada numa comunidade ribeirinha. Nesse espaço geográfico as ruas são formadas por rios, como veremos num desenho construído por um dos alunos. As informações foram organizadas a partir do planejamento do docente e seu relato de experiência. Por isso, durante a discussão surgiram trechos da fala do professor e imagens (autorizadas para estudo e publicação) dos resultados das aulas. 
A prática discutida nesse artigo refere-se à organização e desenvolvimento de duas sequências de atividades a partir dos seguintes livros de literatura infantil: Chapeuzinho Vermelho, uma aventura borbulhante e Eu, um quadrado? A primeira história é uma adaptação do conto "Chapeuzinho Vermelho". É a história de um menino, uma avó, um grande Lobo Mau e um garrafão de refrigerante delicioso. Lynn e David Roberts (autores da obra) deram um toque de imaginação à história clássica e criaram uma imperdível e borbulhante aventura. A segunda, conta a história de um quadrado que vivia se interrogando quem era realmente. Até um dia ouvir alguém dizer: "- Olhe um quadrado!"

$\mathrm{Na}$ primeira história (Chapeuzinho Vermelho, uma aventura borbulhante) foram abordados com os alunos conhecimentos sobre movimentação e localização no plano a partir de mais de um referencial, construção e leitura de mapas, lateralidade e outros conhecimentos relacionados ao tema espaço e forma. No segundo livro (Eu, um quadrado.), tratou-se sobre conhecimentos matemáticos acerca da geometria plana, reconhecimento de figuras planas, definições, regularidades, características das principais figuras planas e outros. Para isso foram construídas e aplicadas duas sequências de atividades.

A primeira sequência de atividades teve como base o livro "Chapeuzinho Vermelho, uma aventura borbulhante". Ela foi desenvolvida em 20 horas de aula e tinha como objetivo identificar lugares usando mais de um ponto de referência; localizar-se e movimentar-se nos pontos de referência e desenvolver as noções de referência espacial (lateralidade). 0 conteúdo abordado foi lateralidade, construção e leitura de mapas e de itinerário. O material necessário para o desenvolvimento dessa sequência de atividade foi cartolinas, canetas coloridas, régua, lápis de grafite, quadro branco, pincel piloto, papel A4 e lápis de cor.

A atividade deu-se primeiramente pela leitura e exploração da história. Alguns questionamentos nortearam a leitura: sobre o que o livro trata? Qual foi o caminho percorrido por Chapeuzinho Vermelho até a casa da vovozinha? Ele poderia fazer outro percurso? Qual? Em seguida, os alunos receberam uma folha de papel A4 e foram desafiados a desenhar o caminho que chapeuzinho fez para chegar até a casa da vovozinha indicando pontos de referência. Depois, as crianças aproveitaram para desenhar o percurso de sua casa até a escola, também indicando pontos de referência. Na sequência, os alunos trocaram os mapas para tentarem ler o caminho traçado por cada colega. Por fim, a história foi lida novamente e os alunos foram indicando em seus mapas o percurso do Chapeuzinho Vermelho. Ao finalizar as sequências de atividades, foram recolhidos os registros dos alunos para que pudéssemos discutir sobre os conhecimentos matemáticos e linguísticos mobilizados pelos alunos durante o desenvolvimento das atividades em sala de aula.

Na segunda sequência de atividades o trabalho foi realizado com o livro "Eu, um Quadrado?". Ela foi desenvolvida em 16 horas de aula e teve como objetivos, identificar os elementos essenciais para construção de quadrados e retângulos, reconhecer elementos que as formas geométricas possuem, tais como, faces, arestas e vértices e ampliar o conhecimento sobre as figuras geométricas planas por meio de suas principais características (número de lados, ângulos e vértices). Os conteúdos matemáticos dessa sequência foram: Figuras Planas (quadriláteros). Os materiais básicos necessários para a realização das atividades foram cartolinas, canetas coloridas, régua, lápis de grafite, 
dicionários, quadro branco, pincel piloto, pincel para quadro branco, livros didáticos e outros. A atividade foi organizada em momentos distintos de aprendizagem.

No primeiro momento de aprendizagem foi apresentado e lido o livro "Eu, um Quadrado?". Exploraram-se bastante as figuras, o título da história e as falas dos personagens, ou seja, inicialmente fez-se um trabalho de pré-leitura (uma forma de antecipação do conteúdo da história). Em seguida, a turma foi dividida em grupos no qual tinham como objetivo indicar as características do quadrado a partir da história (número de lados, ângulos, vértices etc.). Os alunos utilizaram dicionários e o livro didático de matemática para compreender alguns conceitos tratados na história. Depois, sob a orientação do professor, desenharam em cartolina, quadriláteros e triângulos e explicaram suas características e o que os diferenciavam. Além disso, fizeram pesquisas nos livros didáticos sobre a classificação das figuras geométricas de acordo com o número de lados e os ângulos. Por fim, cada grupo apresentou seus desenhos e expuseram suas ideias sobre os conceitos geométricos estudados e ao final deixaram expostas suas produções no mural da escola para que todos pudessem visualizar suas produções.

\section{Os resultados}

Primeiramente foi apresentada aos alunos a leitura do livro Chapeuzinho Vermelho, uma aventura borbulhante. Após explorarem a leitura os alunos foram desafiados a desenhar o trajeto que o garoto da história tinha feito da casa dele até a casa de sua avó. Com isso, foram orientados a prestar bastante atenção nos detalhes da história e que fizessem anotações dos locais por onde Chapeuzinho Vermelho tinha passado. Neste momento todos os alunos ficaram concentrados na atividade. Vejamos uma produção:

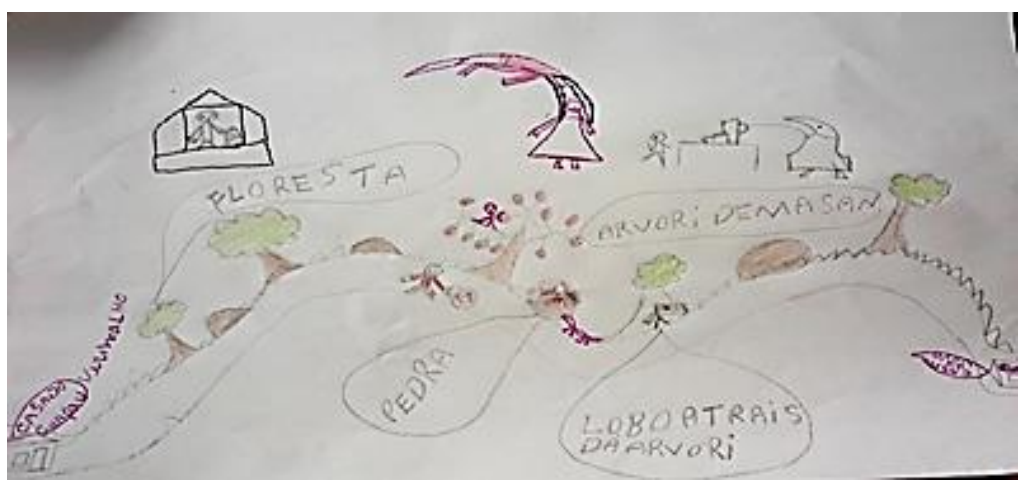

Figura 01: Produção dos alunos Fonte: Trabalho do aluno

Nessa atividade percebe-se que o trabalho com a leitura do texto literário possibilitou que os alunos mobilizassem conhecimentos matemáticos relacionados com a geometria, especificamente, sobre movimentação e localização no espaço. Pois nessa atividade percebemos que o aluno representa informalmente a posição de pessoas e objetos, e ainda, dimensiona espaços por meio do desenho do trajeto feito pelo personagem da história. Com isso, desenvolveu noções de tamanho, de lateralidade, de localização, de direcionamento, de sentido e de vistas. Ele conseguiu identificar e descrever a movimentação de pessoas e objetos de mais de um referencial, além de identificar mudanças de direção e de sentido. Sobre esse tipo de trabalho Fonseca (2009) afirma que: 
[...] o ensino de geometria deve contribuir para ampliar e sistematizar o conhecimento espontâneo que a criança tem do espaço em que vive. Perceber e organizar o mundo físico leva à representação e à modificação desse espaço, que é o que fazem, por exemplo, os desenhistas, os topógrafos, os engenheiros e os arquitetos (FONSECA, 2009, p. 49).

Portanto, nessa atividade os alunos, a partir da leitura, conseguiram a indicar os pontos de referências que haviam ouvido na história, nesse caso, percebemos que a noção de espaço foi ampliada. Passaram de uma geometria topológica (geometria do espaço vivido) para uma geometria projetiva (geometria por meio de perspectivas). Além dos conhecimentos matemáticos mobilizados pela atividade percebemos que essa prática de ler e escrever nas aulas de matemática contribui para a alfabetização linguística das crianças e ainda amplia o raciocínio lógico matemático dos alunos. Essa prática poderia estar presente em todas as salas de aula de alfabetização, independentemente da disciplina. Vejamos o que relata o professor da turma:

Eu nunca tinha ministrado uma aula dessas. Primeiro fiquei pensando sobre o que ensinar de matemática tomando esse livro como referência, já que ele, a priori, não traz nada de conteúdo matemático, mas quando parei para refletir melhor, e depois da conversa que tive com o meu professor formador, percebi que era possível sim. Os alunos estranharam um pouco, mas depois eles entenderam e acharam fácil a aula de geometria. Gostaram principalmente porque envolvia a realidade deles, sua comunidade (Relato de experiência do professor alfabetizador).

$\mathrm{Na}$ fala do alfabetizador percebe-se que essa atividade possibilitou também conduzir os alunos ao reconhecimento de si próprios e da realidade que os circundam. Pois, a convivência de forma lúdica e prazerosa com textos literários favorece a formação do espírito critico do leitor, aguça o seu desejo de transformar a realidade inserindo outras formas de ser e estar no mundo. Portanto, além do que foi comentado, essa atividade integrando língua portuguesa e matemática, rompeu com uma prática que se manifesta em muitas aulas de geometria, ignorar os sentidos, o próprio corpo e as experiências dos estudantes em relação ao espaço, reduzindo o estudo da geometria a figuras planas. Vale a pena destacar, a importância de explorar os conhecimentos sobre ocupação do espaço que as crianças trazem, o vocabulário que usam, os esquemas de representação que possuem e as noções de lateralidade que elas já têm. Estes são cuidados iniciais muito importantes, tanto porque muitos dos alunos não passaram por um processo de alfabetização matemática.

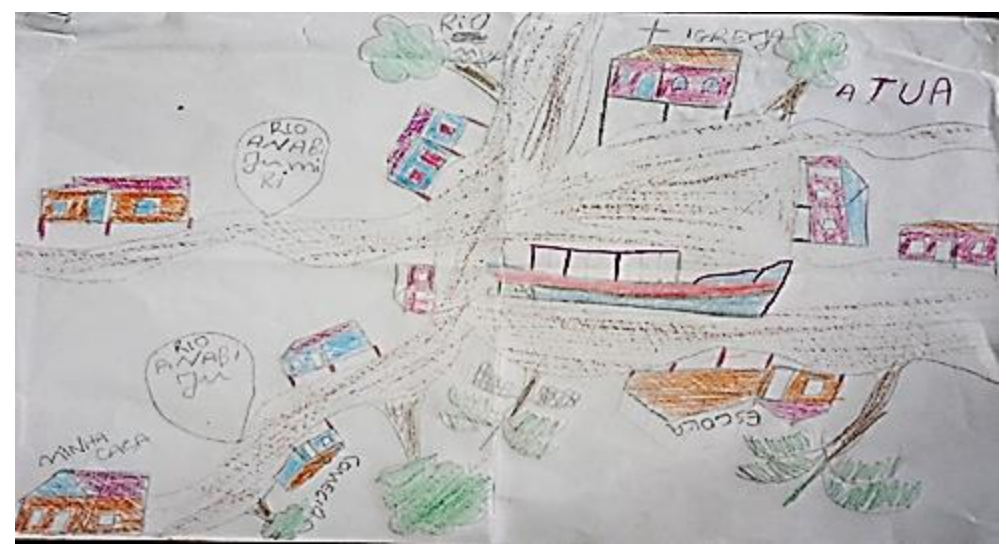

Figura 02: Produção dos alunos Fonte: Trabalho do aluno 
Para continuar ampliando os conhecimentos matemáticos sobre geometria, foi solicitado logo em seguida, que construíssem um mapa indicando o trajeto que os alunos fazem de suas casas até a escola, sempre tendo o cuidado de indicar pontos de referência para facilitar a leitura da imagem. Essa tarefa tinha como objetivo ampliar o conhecimento dos alunos no que concerne a construção de itinerários.

Essa atividade possibilitou que os alunos reconhecessem seu próprio corpo como referencial de localização e deslocamento no espaço, observar, experimentar e representar posições de objetos em diferentes perspectivas, considerando diferentes pontos de vista e por meio de diferentes linguagens. Nessa tarefa, os alunos puderam expor a noção de espaço que possuem em relação ao local onde moram, recorrendo ao uso de vários pontos de referência.

Corroborando com Fonseca (2009), as crianças, desde o seu nascimento, procuram conhecer e explorar o espaço em que vivem, dirigindo suas ações e sua atenção nesse sentido. Elas vão explorando esse mundo geométrico a partir de suas necessidades, ou de sua curiosidade, construindo, assim, certa competência geométrica.

A imagem permite observar que o aluno usa vários pontos de referências em seu percurso - rio, barco, comércio, igreja, casas, sua casa, árvores e a escola - mostra sua relação e perspectiva do ambiente em que convive diariamente. De um modo geral, os estudantes expressaram por meio de seus desenhos as experiências diversificadas que possuem em relação à região em que vivem, ou mesmo em relação aos locais em que podem ter vivido ou dos quais podem ter ouvido falar. Pois, fica clara a relação que eles estabelecem com os diferentes espaços mostrados nos mapas. Vejamos o relato do professor alfabetizador sobre essa aula:

Nessa aula de construção de itinerários os alunos puderam vivenciar seu cotidiano e pensar sobre a matemática na nossa vida. E a minha aula ficou mais interessante. Percebi que a escolha do livro de literatura foi importante para o meu planejamento e para a aprendizagem dos alunos. É que eles aprenderam a linguagem da geometria (Relato de experiência do professor alfabetizador).

De acordo com o relato do professor, essa atividade mobilizou conhecimentos matemáticos extremamente importantes para a construção e ampliação do senso espacial dos alunos, não apenas pelo fato de utilizarem o vocabulário próprio da geometria, mas também, no que diz respeito à construção de um vocabulário autônomo e diversificado para indicar a localização e a movimentação de objetos e pessoas num determinado espaço, seja ele vivido ou imaginado. É nessa perspectiva que Fonseca (2009, p. 72), afirma que "as experiências, o conhecimento, o interesse e as necessidades dos alunos devem ser considerados pelo professor ao decidir o percurso que fará com eles na abordagem da geometria".

Outra atividade matemática envolvendo a leitura de texto literário foi desenvolvida a partir da obra "Eu, um quadrado?". Nessa atividade tínhamos o objetivo que abordar elementos da geometria euclidiana (a geometria das figuras e formas geométricas). Como a história tratava de uma figura geométrica que tinha uma grande dúvida sobre o que era (quadrado, retângulo, triângulo, trapézio etc.), os alunos foram orientados a observarem e anotarem as características do quadrilátero da história, e depois, desafiados a escrever um argumento para convencer os colegas de que o quadrilátero da história era um quadrado. Um grupo de alunos escreveu o seguinte argumento: 


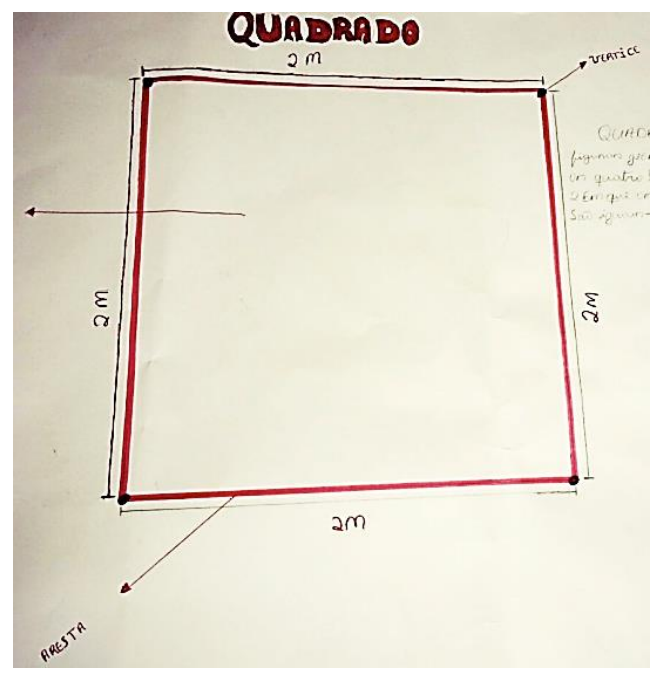

Figura 03: Produção dos alunos Fonte: Trabalho dos alunos

Além de desenhar a figura com as medidas dos lados iguais (2 metros), escreveram que essa figura era um quadrado porque é "uma figura geométrica que tem os quatro lados e os quatro ângulos iguais. E o dado tem seis iguais". Nessa atividade percebemos que os alunos puderam desenvolver e ampliar conhecimentos geométricos acerca da percepção das semelhanças e diferenças entre figuras geométricas por meio de elementos da geometria euclidiana (medida dos lados, medida dos ângulos, números de lados, vértices etc.). Essa tarefa foi avaliada pelo professor alfabetizador como complexa.

Essa história foi mais difícil para os alunos porque falava de assuntos "pesados" da geometria: vértices, arestas, lados e ângulos. Mas quando fomos lendo e entendendo a história as coisas foram ficando mais fáceis. Utilizamos para facilitar dicionário e o livro didático. Foi bom porque os alunos conheceram outros assuntos da geometria ao invés de saber só o nome das figuras (Relato de experiência do professor alfabetizador).

Pelo relato do alfabetizador nota-se que esse trabalho possibilitou que os alunos descrevessem, comparassem e classificassem as figuras planas (no caso da nossa atividade os quadriláteros) por características comuns, mesmo apresentadas em diferentes disposições, descrevendo também por meio da oralidade. Além de mobilizar saberes matemáticos específicos do bloco de conteúdos da geometria. Vejamos outro exemplo:

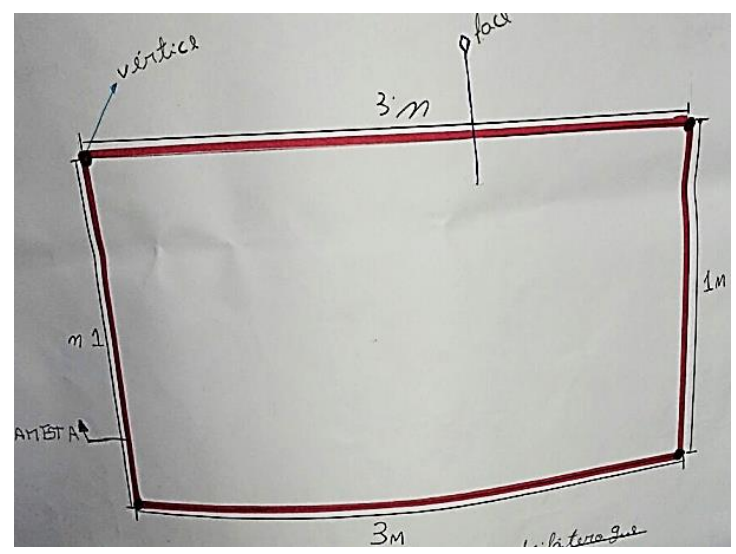

Figura 04: Produção dos alunos Fonte: Trabalho do aluno 
Esse grupo de alunos recorreu a alguns elementos geométricos para justificar que esse quadrilátero representado na figura era um retângulo. Face, vértice e aresta, mesmo que utilizados de forma equivocada, foram os elementos geométricos utilizados para tentar validar seus conhecimentos geométricos. O mais importante nessa atividade foi a construção da argumentação utilizando a linguagem matemática por meio da leitura, da escrita e da oralidade. Percebemos ainda que as atividades de geometria foram apresentadas, de um modo geral, por meio de desenhos construídos pelos alunos, e isso facilitou a compreensão dos conteúdos matemáticos. Mas Fonseca (2009) chama a atenção dos professores no seguinte sentido no que concernem atividades matemáticas com desenho:

Não é, entretanto, a simples atividade de desenhar que vai desenvolver a capacidade de representar uma figura geométrica. Muitas vezes, propomos aos alunos atividades que envolvem desenhos sem nenhuma orientação no sentido de permitir que avancem ou ampliem suas possibilidades de representação (FONSECA, 2009, p. 77).

Por isso, que além das orientações dadas sobre o desenvolvimento e os objetivos das atividades, os alunos foram orientados a pesquisar em dicionários e livros didáticos de matemática o significado de algumas palavras ou expressões referentes à geometria. Além disso, procuramos identificar e considerar o significativo conhecimento que os alunos tinham sobre geometria, para somente depois, propor as atividades aqui discutidas.

\section{Considerações Finais}

A construção dessa pesquisa possibilitou apresentar, descrever e discutir sobre a importância de promover nas aulas de matemáticas atividades centradas nas práticas de leitura e escrita, e ainda, mostrar que é possível ensinar matemática e língua portuguesa por meio da literatura infantil. Nas atividades propostas percebemos que quando os alunos são colocados diante de situações do seu cotidiano, ou seja, tarefas que propositalmente traduzem situações do seu dia a dia para uma linguagem escolar, como por exemplo, desenhar o trajeto de casa até a escola, fomenta a participação dos alunos na aula, a construção de novas habilidades e ampliação de outras, e possibilita além da alfabetização em língua materna a alfabetização matemática.

O estudo provocou uma reflexão acerca de um ensino de geometria que vá além de ensinar o nome das figuras geométricas. Mostrou que é preciso considerar o ensino da geometria como uma construção humana e histórica, com sua linguagem própria e que também permeia a linguagem cotidiana ("aparar as arestas", "sair pela tangente", "pessoa quadrada" etc.). Percebeu-se que, apesar dos alunos apresentarem muitas dificuldades em relação às práticas de leitura e de escrita na escola, eles participam de diversos eventos de práticas sociais (fora da escola) de leitura e escrita, e por isso, a importância de considerar seus conhecimentos prévios no momento de planejar as aulas.

Sobre a prática do professor alfabetizador, concluímos que por conta de termos tido uma formação fragmentada nossa prática de sala de aula recai num ensino, também, fragmentado. Por isso as dificuldades em trabalhar um ensino de matemática integrado ao ensino de língua portuguesa por meio da leitura de textos literários. Mas podemos afirmar que uma prática pedagógica interdisciplinar é possível. 
Portanto, deveríamos, nós professores da educação básica, fomentar em nossos alunos a prática da leitura nas diversas disciplinas do currículo. Promover um ensino que fortaleça em nossos alunos o interesse cada vez maior pela leitura e, consequentemente, pela matemática, pois acreditamos que muito do fracasso dos estudantes nas aulas de matemática são decorrentes da dificuldade que apresentam na leitura e na escrita.

\section{Referências}

BRASIL. Parâmetros Curriculares Nacionais: matemática. Secretaria de Educação Fundamental. Brasília: MEC/SEF, 1997.

FARIA, Maria Alice. Como usar a Literatura Infantil na sala de aula. 5. ed. São Paulo: Contexto, 2012.

FONSECA, Maria da Conceição Ferreira Reis. O Ensino de Geometria na Escola Fundamental: três questões para a formação do professor dos ciclos iniciais. Belo Horizonte: Autêntica, 2009.

FONSECA, Maria da Conceição Ferreira Reis. Alfabetização Matemática. In: BRASIL. Pacto Nacional pela Alfabetização na Idade Certa: caderno de apresentação. Ministério da Educação. Secretaria de Educação Básica. Brasília: MEC/SEB, 2014.

LOPES, Celi Aparecida Espasandin. Escritas e leituras na educação matemática. Belo Horizonte: Autêntica, 2009. 